Portland State University

PDXScholar

$5-26-2021$

\title{
Identifying the Cost of Preventable Chronic Disease in Prison: Can Illness Prevention of Adults in Custody Save Money?
}

Molly Bineham

Portland State University

Follow this and additional works at: https://pdxscholar.library.pdx.edu/open_access_etds

Part of the Criminology and Criminal Justice Commons, and the Other Public Health Commons Let us know how access to this document benefits you.

\section{Recommended Citation}

Bineham, Molly, "Identifying the Cost of Preventable Chronic Disease in Prison: Can Illness Prevention of Adults in Custody Save Money?" (2021). Dissertations and Theses. Paper 5713.

https://doi.org/10.15760/etd.7585

This Thesis is brought to you for free and open access. It has been accepted for inclusion in Dissertations and Theses by an authorized administrator of PDXScholar. Please contact us if we can make this document more accessible: pdxscholar@pdx.edu. 
Identifying the Cost of Preventable Chronic Disease in Prison:

Can Illness Prevention of Adults in Custody Save Money?

By

Molly Bineham

A thesis submitted in partial fulfillment of the requirements for the degree of

Master of Sciences

Criminology and Criminal Justice

Thesis Committee:

Dr. Christopher Campbell

Dr. Danielle McGurrin

Dr. Mauri Matsuda

Portland State University

2021 


\begin{abstract}
This study investigates the cost of preventable health problems and ailments when compared to other costs of incarceration. The purpose of this study is to examine the impact of imprisonment on the costliest chronic illness. The health of adults in custody related to the general population and the overall fiscal cost of the deadliest chronic illness among incarcerated adults is discussed. Linear regression is used to analyze the occurrence of heart disease and diabetes among adults in custody while controlling for other factors. The results of this analysis provide insight that chronic diseases like heart disease and diabetes should be addressed. This research presents an opportunity for future cost-benefit analysis of cost-effective health promotion and prevention with prisons.
\end{abstract}




\section{Contents}



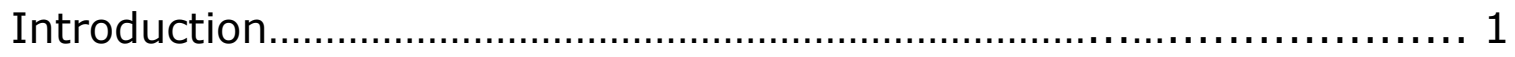



Methodology

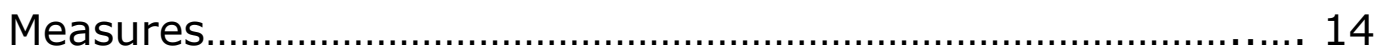

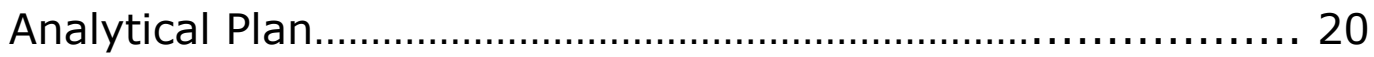

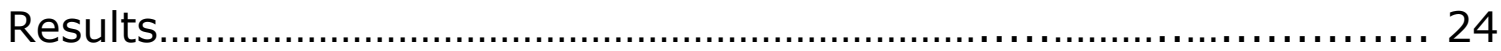

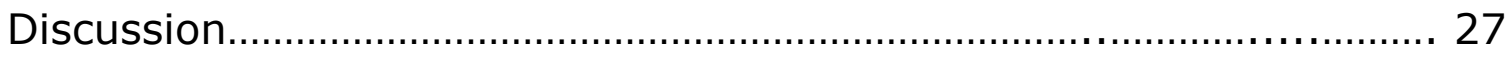

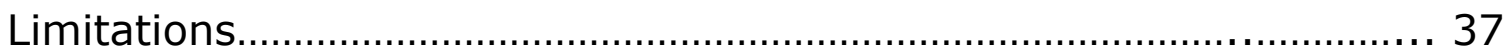

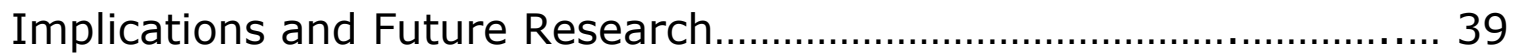

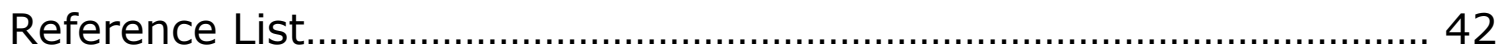




\section{List of Figures}

Figure 1. Example of Cost Conversion Calculation.............................. 14

\section{List of Tables}

Table 1.1 Descriptive Statistics.......................................................... 20

Table 1.2 Average Costs of Incarceration............................................ 22

Table 1.3 Correlation coefficients across cost measures..................... 23

Table 2. OLS models assessing relationships between costs while

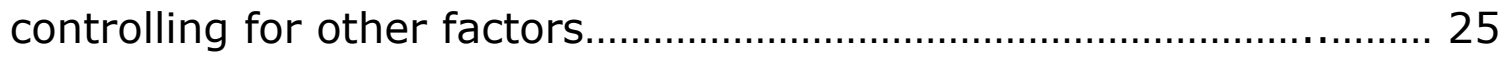

Table 3. T-Test to unpack select variables of Model 3......................... 33 


\section{Introduction}

Considering what penologists have long recognized "prisons do not exist in a vacuum: they are part of the social, economic and moral order" (Jacobs, 1977, p.98), incarceration may be a contributing factor in the perpetuation of chronic illnesses among correctional populations. Chronic illnesses are among the most prevalent and costly health conditions in the United States, affecting nearly half of the population, about $45 \%$, or 133 million (Raghupathi, 2018). Generally, chronic illness is defined as a condition that lasts longer than a year, requires medical attention, and decreases one's ability to participate in daily activities (Anderson, Horvath, 2004). Neglected aspects of the community, particularly healthcare and the associated costs, are often magnified in prisons (Watson, 2004). Areas in which incarceration contributes to chronic illnesses are via conditions of correctional facilities, including exposure to violence, exposure to communicable diseases, and poor nutrition (Udo, 2019). While some correctional facilities may have adequate health care, there is a decline in available health resources (e.g., affordability of private insurance) post-prison that may worsen their chronic illness (Negussie, 2017). As criminal justice agencies across all jurisdictions continue to assess and minimize the impact of carceral practices, it is critical to determine the role of chronic diseases in the context of mass incarceration. 
Mass incarceration in the United States has been a growing and relevant issue since the punitive turn of criminal justice in the 1970 s and tough-on-crime policies such as the War on Drugs (Cullen, 2013). Since the 1970s the number of people incarcerated in the United States has increased by $700 \%$ (Udo, 2019). As the incarcerated population grew, the number of elderly adults in custody grew even faster due to lengthier sentences, creating an aging crisis (Nowotny, 2016). Between 1995 and 2010, the population of adults in custody aged 55 and older grew six times the rate of the overall prison population (Human Rights Watch, 2012).

The incidence of chronic illness increases with age, and most adults with a chronic condition are over the age of 65 (Prasad, 2011). Research has shown that older adults in custody are likely to report one or more chronic health conditions (Lemiux, 2002). There is an argument that those who become incarcerated may develop improved health ${ }^{1}$, but research findings outline the decline of physical and mental health (Wilderman, Wang, 2019). Health inequalities of adults in custody ripple back into the community at their release, affecting the ability to productively reenter society, creating strain on friends and family, and adding to the chronic health epidemic within our

\footnotetext{
${ }^{1}$ The health of some prisoners improve while in prison according to Robinson (2012).
} 
nation. The health disparity caused by incarceration impacts not only the incarcerated but their families, their communities, and the social and economic structure (Bowleg, 2020). Incarceration is assumed to be a method of humane punishment (Nilsen,2007, p.114), a term used to describe a sentence that is not cruel or unusual. Incarceration strives to be humane yet, is debated, as correctional facilities are not all up to the same standards (Smoyer, 2016). In the United States, the level of care prisons legally are responsible for providing is not clear. The Centers for Disease Control and Prevention (CDC) state that preventing chronic illness and managing symptoms when prevention is not possible can reduce the cost of the disease (National Center for Chronic Disease Prevention and Health Promotion (NCCDPH, 2020). The deadliest disease in the United States is heart disease and stroke, one-third of all deaths per year (NCCDPH, 2020), cancer is the second most deadly disease, diabetes the third and obesity is the most common risk factor for all three of these chronic diseases (NCCDPH, 2020). A study done by Udo and colleagues found that a history of incarceration was associated with chronic diseases, even after adjusting for childhood adversity (2019). This research emphasizes the need for further understanding the effects of incarceration on chronic health conditions.

This study investigates the cost of preventable health problems and ailments when compared to other costs of incarceration. The 
purpose of this study is to examine the impact of imprisonment on the costliest chronic illness. While focusing on risk factors for chronic diseases, this paper addresses how the environment of correctional facilities affects health behaviors. My research and analysis goals are to understand (1) how the health of adults in custody relate to the general population, (2) and the overall fiscal cost of the deadliest chronic illness among incarcerated adults. 


\section{Literature Review}

The concern for public health and public safety is pressing and important, as all nations strive to improve overall health and reduce crime (United Nations, 2021). Exemplifying this is the statement by Richard H. Carmon, a United States surgeon general, "Public safety is public health; public health is public safety" (The Pew Charitable Trusts, 2017, p.3). Threats to one's safety are just as significant as threats to one health-the intersection of these aspects of quality of life meet at prison health care. Research and promotion of prison health could tackle the social determinants of health (Woodall, 2014). The population of correctional facilities is not a diverse group of citizens but disproportionately representing the urban poor (James, 2018; Marquart 1996). The minority populations with lower socioeconomic status have higher rates of chronic diseases like cancer, diabetes, and hypertension (Price, 2013; Marquart, 1996). The prevalence of chronic disease risk factors is rooted in race, economic, and social inequalities borne disproportionately by communities of color (Davis, 2007). One reason for this higher rate of risk factors is due to targeted corporate marketing, used to promote harmful products in racially segregated neighborhoods. Such examples including tobacco and unhealthy foods can increase the risk of disease and overall health for racially and economically marginalized community groups (Bailey, 2017). Woodall and colleagues 
note that disease is more likely in prison populations, and minorities disproportionately exposed to risk factors are more likely to be incarcerated (2014). The prison population is primarily adults from communities burdened with health disparities and a decline in an already low baseline of health (Woodall, 2014). The most prevalent chronic diseases among adults in my sample are heart disease and stroke, diabetes, and cancer.

Correctional organizations should consider chronic disease prevention measures to decrease health disparities and lower healthcare costs in prisons cost-effectively. The CDC states that reducing risk factors to prevent the likelihood of getting chronic disease is possible. The key risk factors are smoking, poor nutrition, lack of physical activity, and excessive alcohol use (NCCDPH, 2020). Smoking is the leading cause of preventable death in the United States (U.S. Health and Human Services, 2020). Even after a lifetime of tobacco use, smoking cessation can save lives and reduce the risk of heart disease, cancer, diabetes type 2, and lung disease (NCCDPH, 2020). Proper nutrition, a balanced healthy diet, quality sleep and physical activity can prevent, and delay heart disease, type 2 diabetes, and other chronic diseases caused by obesity (NCCDPH, 2020). Excessive drinking can lead to high blood pressure, various cancers, heart disease, stroke, and liver disease. Alcohol addiction 
management and moderate drinking can lower the risks for chronic illness. Regular doctor visits to manage and catch chronic illness early also will increase the likelihood for prevention. The management of chronic diseases is crucial to saving lives and is cost-effective (CDC, 2021).

Chronic disease is not only deadly but also highly costly. Heart disease and stroke cost our healthcare system $\$ 214$ billion per year (Ej, 2018). In an observational study of about 12,000 patients observed for seven years, the average cost of cardiovascular disease was nearly $\$ 19,000$ per patient per year, according to the American Journal of Managed Care (2004). The national cost of cancer was $\$ 157$ billion in 2012 and reached $\$ 174$ billion by 2020 . (National Cancer Institute, 2018). The cost of treating cancer is about $\$ 2,500$ a month per patient after insurance; without insurance, out of pocket costs could add up to over $\$ 12,000$ (The Mesothelioma Center, 2018). The American Diabetes Association estimated in 2017 that diagnosed diabetes cost $\$ 327$ billion, a $26 \%$ increase from the $\$ 245$ billion in 2012. This estimated cost of diabetes includes both the cost of type 1 and 2 diabetes, although $90-95 \%$ of all Americans with diabetes have type 2 (NCCDPH, 2020). The American Diabetes Association reported that people with diagnosed diabetes incur about $\$ 10,000$ per year of medical expenditures attributed to diabetes. 
Considering prisons are a microcosm of the larger society, we can expect the costs of chronic illnesses to comprise a similar proportion of health and overall costs of incarceration. Adults in custody are expected to have more health problems relative to the general public given their higher levels of poverty, addiction, mental and physical health issues (Gregory, 2005). The Pew Charitable Trusts conducted a report on spending trends in prison health care. This report was the first-of-its-kind and remains today the only report exploring the cost of prison health care across the United States. Pew's research found that in 2015, collectively, the departments of corrections collectively spent $\$ 8.1$ billion on health care services within prisons for adults in custody, about a fifth of prison expenditures (PEW, 2017). Health care services make up a significant portion of correction expenditures and are essential when examining cost-effectiveness. The total per capita expenditure for corrections increased between 1982 and 2003, a per capita increase of $423 \%$ (Hughes, 2003). The expenditure for corrections accounted for the highest increase of justice functions, in 1992 United States Corrections spent $\$ 9.0$ billion on corrections and in 2003 the spent $\$ 60.0$ billion (Hughes, 2003).

In the United States, chronic diseases account for most health care costs (NCCDPH, 2020). The Pew and Vera Institutes found this 
true in 2015 and continues to be the nation's leading health care cost. The prevalence rate and costs of chronic disease and health care are not absent from prisons and may worsen in such settings. The impact of chronic disease is especially prevalent in prisons because of the large number of older adults in custody. The number of older individuals, 55 or older, has increased over time and has risen from three percent to 11 percent from 1999-2015 (Vera, 2017). The Bureau of Justice Statistics found older adults in custody are more susceptible to costly chronic medical conditions (Greene, 2018). Older adults in custody experience the effects of age sooner than people outside prison because of issues that have occurred before incarceration, such as higher rates of poverty, substance use disorders, as well as inadequate preventive and primary care (Greene, 2018). Factors of stress linked to the isolation and loneliness within prisons and the anxiety of prison cultures of violence can also play into the likelihood of chronic illness prevalence (Greene, 2018).

Vera's research in 2010 notes that elderly adults in custody have five times as many visits to health care facilities than adults not incarcerated of the same age. This difference leads to an increased cost of incarcerate geriatric individuals than younger adults in custody. According to a 2004 report from the National Institute of Corrections, the annual cost to imprison an older person was an estimated 
$\$ 70,000$, three times more than younger individuals (Vera,

2010). This research suggests that early release of adults in custody may be cost effective for these agencies and taxpayers. Monitoring and measuring the cost and effectiveness of releasing older adults in custody who may save money and not threaten society is essential to create change.

Both Pew's and Vera's research emphasize the need to analyze and examine health care services, what population groups use these services the most, and how. A clear understanding and detailed analysis of health care services are necessary to provide adequate care sustainably and cost-effectively. Little research exists on the costs and outcomes of prison health care. The public finance data shared by the Bureau of Justice Statistics and Census does not provide a breakdown of average health expenses per adult in custody. Prior research has emphasized the impact of an aging incarceration population. The research for prison health promotion in the early and mid-2000s focuses primarily on mental health, substance abuse, and infectious diseases such as HIV/Aids. (Watson, 2004). There is a lack of research on preventable chronic illness. A focus on preventing the health issues of elderly adults in custody could decrease the number of tax dollars going towards treatment. Cost-effective programming with long-term payoffs could improve prison health care and further implications (Pew, 2017). 
The cost of correctional health care is critical to understanding the variation in carceral spending. Knowing and understanding the quality and quantity of health care can assist states in their ability "to achieve universal goals: meeting constitutional obligations, protecting public safety, strengthening public health, and practicing fiscal prudence" (PEW, 2017, p.2). Information and data surrounding health care are crucial for states to have the money to make changes and improve proficiency. Four core goals that are integral to prison health care are constitutional obligations, public health, public safety, and fiscal prudence (Huh, 2017). Constitutional changes have dramatically improved the standard for health care within prisons in the past fifty years. Before 1970 prisons not only removed adults in custody's rights and freedom but also put their health at risk (McDonald, 1999). In 1991 a statute was put in place after the Fernandez vs. the United States case, stating that care must be "reasonably commensurate with modern medical science and a quality acceptable within prudent professional standards" (McDonald, 1999, p. 436). The Association of State and Territorial Health Officials indicate in the National Public Health Performance Standards that the goal for all states is to advance health equity and optimal health for all (2021). However, states must still operate health care systems within parameters to contain cost and operate with finite resources. The importance of sustainable and fiscally 
efficient systems is central for achieving high-performance health care systems.

The goals within correctional facilities across the nation are common yet are significantly varied and evident by the per adult in custody expenditures among states. In 2015, spending on jails and prisons reached $\$ 87$ billion, a 1,000\% increase since 1975 (Bronson, 2018). As of May 2014, spending on corrections ranked as the thirdhighest category of general fund expenditures in most states, behind Medicaid and education (Travis, 2014). The data submitted to Pew and Vera indicate that the typical state department of corrections in 2015 spent $\$ 5,720$ per adult in custody to provide a range of health care services. The medical costs of an adult in custody, age 55 or older, were more than four times the associated costs for younger adults in custody (Vera, 2015). Prison health care costs are an increasing drain on state and federal budgets, and costs remain high for former prisoners (Ahalt, 2011). The Bureau of Justice Statistics points to factors that contribute to the range of spending. These include "pre-incarceration access to adequate community care, regional medical prices, staffing and compensation levels, facility capacity and related economies of scale, and incidences of high-risk behaviors and associated disease burdens like the prevalence of particular high-cost populations and certain costcontainment strategies, such as age and copays" (PEW, 2017, 
p.52). Although the methods differ, as Rodney Ballard, former commissioner of the Kentucky Department of Corrections, said, "states cannot privatize or outsource their responsibility" (PEW, 2-17 p.11).

Prisoner information historically is left out of public knowledge. Former President Barack Obama was the first president to step foot in federal prison and shed light on how prisons function and look. Data and research available to the public do not often include health and human services within correctional facilities. The connection between health care focusing on chronic illness and the disparities of chronic disease among adults in custody is lacking. Few studies have investigated the status and outcomes of chronic disease and health management within correctional facilities. Further research could lead to opportunities for cost savings in corrections without sacrificing service quality. 


\section{Methodology}

This study will identify the cost of preventable disease among a sample of adults in custody using survey data collected in 2004 . Specifically, this study uses data from the Survey of Inmates in State and Federal Corrections Facilities in the United States compiled from the Bureau of Justice in 2004 (Inter-University Consortium for Political and Social Research [4572]), which is a combination of a survey of adults in custody in state and federal correctional facilities. A total of 11,569 adults in custody participated in this study. Respondents provided information about their place of residency, demographic data, current health and wellbeing specific diseases they currently have, tobacco use, levels of physical activity, among other information (ICPSR 4572).

\section{Measures}

My research hypothesis is that adults in custody with a chronic illness will significantly increase the cost of incarceration. The overall costs attributed to chronic illness disease and related symptoms are greater than the overall cost of housing adults in custody while simultaneously preventing illness. The calculations of average cost of imprisonment and each average cost of chronic disease are converted 
into 2021 dollars using the associated average annual Consumer Price Index (CPI) provided by the U.S. Bureau of Labor Statistics. ${ }^{2}$

Figure 1. Example of Cost Conversion Calculation

$$
\begin{gathered}
(2021 \text { CPI } / 2000 \text { CPI }) * 2000 \text { cost }=2021 \text { cost } \\
(261.6 / 129.8) / * \$ 100=\$ 154.97
\end{gathered}
$$

The average cost of incarceration per state was converted to 2021 United States dollars (USD) using survey data conducted by Vera in 2015. Vera's survey was distributed to all states and collected data on the number of prisons, employees, adults incarcerated, and prison expenditures (Mai \& Subramanian, 2017). Vera's report emphasizes that providing adequate living conditions makes prisons more expensive. The higher levels of health care for a population with physical and mental health concerns and staff, recreational and educational programs, maintenance, and operationalization costs contribute to increased costs (Mai \& Subramanian, 2017). Among the 45 states that responded to the survey, the collective total state expenditure on prisons was almost $\$ 43$ billion. The states' entire prison costs vary greatly, mainly depending on the size of the prison

\footnotetext{
${ }^{2}$ Converting costs to the present year is a strategy to estimate the cost-of-crime (Dominquez, 2015).
} 
system. California's total prison costs were the highest at $\$ 8$ billion while North Dakota's prison costs were the lowest at \$65 million (Mai \& Subramanian, 2017). The average price per adult in custody is calculated by taking the total costs and dividing it by the average daily prison population per state. Vera found that the average cost per inmate was $\$ 33,274$ in 2015 and ranged from $\$ 14,780$ in Alabama and $\$ 69,355$ in New York. Using the Inter-university Consortium for Political and Social Research (ICPSR) data in my research, I assigned the average cost of imprisonment converted to 2021 dollars to each adult in custody in my data set depending on the state prison.

In the analysis each adult in custody was assigned an average cost of incarceration based on the average cost of incarceration per person that was recorded in their state, based on Vera's report. For example, as the baseline cost all adults in custody who are incarcerated in Oregon are assigned the average cost of incarceration per adult in custody based on Vera's 2015 report $(\$ 44,021)$, converted to 2021 USD $(\$ 45,968)$.

The dependent variable in this study measures the cost of the two most costly chronic illnesses, heart disease, and diabetes. The CDC reports that heart disease costs the health care system $\$ 214$ billion per year, and diabetes costs $\$ 237$ billion per year (2017). Heart disease and diabetes are also two of the deadliest chronic illnesses, 
heart disease taking one-third of all deaths and diabetes the seventh leading cause of death and a leading risk factor for heart disease (CDC, 2017). Heart disease and diabetes are the most prevalent chronic illnesses in my data set. The dependent variable is determined by summing the average cost of incarceration per state adjusted for age-associated expenses which is discussed in the following paragraph, plus the price of diabetes and heart disease.

A 2013 report by the Bureau of Prisons found that, on average, adults in custody age 50 and older cost eight percent more than those 49 and younger. This cost difference between older and younger adults in custody was primarily driven by medical needs, including medication for aging adults in custody (BOP, 2013). In my analysis, the average cost of heart disease and diabetes were derived from a report published by Medicare (CMS Chronic Condition Data Warehouse, 2018) and the average cost per person per year in each state was converted from 2018 USD to 2021 USD. While the cost of heart disease and diabetes differ for each person depending on insurance coverage, state, and prison, the Medicare costs provide an average baseline cost.

In regard to the example used previously, each adult in custody in Oregon is associated with the baseline cost average cost of incarceration in Oregon plus $8 \%$ if they are 55 and older $(\$ 45,968+$ $\$ 3,677=\$ 49,645)$. If they have heart disease the average cost of 
having heart disease in Oregon, converted from Medicare's 2018 $(\$ 18,967)$ to 2021 USD $(\$ 22,753)$ is added to the total associated cost $(\$ 49,645+\$ 22,756=\$ 72,396)$. If the adult in custody currently has diabetes the average cost of having diabetes in Oregon, converted from Medicare's $2018(\$ 14,605)$ report to 2021 USD $(\$ 17,520)$ is added to the total associated cost $(\$ 49,645+\$ 17,520=\$ 67,165)$.

The independent variable in this study was recoded into a dummy variable. The variable, whether or not the adult in custody has heart disease or diabetes, is grouped into two groups, whether they have one of these diseases (yes $=1$ ) or whether they do not have either of these diseases $(\mathrm{no}=0)$.

Table 1 provides a breakdown of the demographic and control variables used in the analysis. The current study's analysis categorizes the data by the Census region: west, mid-west, southwest, southeast, and northeast. The dependent variable, cost, is continuous and measured in dollars. The demographic variables are also coded into dummy variables, sex of the adult in custody ( $1=$ male, $0=$ female), age of the adult in custody ( $1=$ age over $50,0=$ age younger than 50$)$ and race ( $1=$ White, $0=$ Nonwhite), cancer ( $1=$ currently has cancer, $0=$ does not currently have cancer), obesity ( $1=$ BMI classifies as obese, $0=$ BMI does not classify as obese), tobacco use ( $1=$ uses tobacco, $0=$ does not use tobacco), asthma ( $1=$ 
has asthma, $0=$ does not have asthma) and exercise ( $1=$ has exercised in the last 24 hours, $0=$ has not been physically active in the previous 24 hours).

The additional variables included in the model also contribute to the increased cost of incarceration. The medical-related cost of using tobacco, having cancer, and the cost of obesity was calculated and added to account for other possible explanations for the increased cost. The medical cost of obesity was calculated in a systematic review conducted by the Division of General Internal Medicine and Center for Human Nutrition at the University of Colorado Denver in 2008. This research found that the average 2008 annual per-person direct medical cost of being overweight was $\$ 266$, and obesity was $\$ 1723$ (Tsai et al.). The classification of normal, overweight, and obese is defined by the CDC using Body Mass Index (BMI). BMI is a person's height in kilograms divided by the square height in meters (CDC, 2021). Overweight is defined as having a BMI of over 25 and less than 30 , and obesity is defined as having a BMI of 30 or higher. BMI does not accurately measure body fat; instead, it is moderately correlated with direct measures of body fat, like waist circumference or skinfold thickness measurements (CDC, 2021). People with increased muscle may not be considered overweight or obese, even with a BMI above 25 (CDC, 2021). The possible inaccurate BMI scores are 
accounted for by only including adults in custody with a BMI of 30 or higher were associated with an increased cost. The costs were converted to 2021 USD and classified. The classifications are due to the medical and health risks the obesity poses; according to Medline Plus, a BMI between 30 and 35 is classified as low risk costing an average of $\$ 323.18$ a year, a BMI between 35 and 40 is moderate risk costing an average of $\$ 1,208.27$, and a BMI over 40 is a high risk, costing $\$ 2,903.36$ (2021).

\section{Table 1.1 Descriptive Statistics}

\begin{tabular}{|c|c|c|c|c|}
\hline \multirow{2}{*}{$\begin{array}{l}\text { Total Sample } \\
(\mathbf{N = 1 4 4 9 9 )} \\
\text { Sex (Male) }\end{array}$} & \multicolumn{2}{|c|}{$\begin{array}{l}\text { Heart Disease } \\
\quad(N=1337)\end{array}$} & \multicolumn{2}{|c|}{$\begin{array}{l}\text { Diabetes } \\
(N=699)\end{array}$} \\
\hline & 680 & $50.86 \%$ & 437 & $62.52 \%$ \\
\hline Age (Under 55) & 228 & $17.05 \%$ & 187 & $26.75 \%$ \\
\hline Race (White) & 549 & $41.06 \%$ & 292 & $41.77 \%$ \\
\hline Weight (Obese) & 258 & $19.30 \%$ & 284 & $40.63 \%$ \\
\hline Cancer (Current) & 36 & $2.69 \%$ & 11 & $1.57 \%$ \\
\hline Tobacco (Current) & 934 & $69.86 \%$ & 583 & $83.40 \%$ \\
\hline Asthma (Current) & 245 & $18.32 \%$ & 134 & $19.17 \%$ \\
\hline State Region (West) & 408 & $30.52 \%$ & 259 & $37.05 \%$ \\
\hline State Region (Midwest) & 165 & $12.34 \%$ & 105 & $15.02 \%$ \\
\hline $\begin{array}{l}\text { State Region } \\
\text { (Southwest) }\end{array}$ & 39 & $2.92 \%$ & 20 & $2.86 \%$ \\
\hline $\begin{array}{l}\text { State Region } \\
\text { (Southeast) }\end{array}$ & 165 & $12.34 \%$ & 102 & $14.59 \%$ \\
\hline State Region (Northeast & 125 & $9.35 \%$ & 75 & $10.73 \%$ \\
\hline
\end{tabular}

Considering that the cost of incarceration varies across the United States, it is crucial to capture such variation as best as possible 
when investigating how much health care encompasses. Pew's research found that in 2015, the California Department of Corrections and Rehabilitation spent $\$ 19,796$ per adult in custody on health care (PEW, 2017). In 2011, Texas spent a total of $\$ 229,318,493$ on health care and New York State's Department of Corrections and Community Supervision spent $\$ 145,461,000$ in the fiscal year of 2019 . Table 1.2 displays the dependent variable and each variable included. When looking at the population of adults in custody in 2004 who participated in the survey conduction by the ICPSR, the average cost to incarcerate someone with heart disease or/and diabetes is $\$ 157,585$ annually in USD, ranging from $\$ 91,247.66$ to $\$ 584,516.80$. The annual average price of incarceration in USD is $\$ 35,018.28$, ranging from $\$ 15,43340$ in Alabama to $\$ 72,423$ in New Mexico. The average overall yearly cost of having diabetes, according to Medicaid, is $\$ 20,416.72$, ranging from $\$ 11,08740$ in Washington and $\$ 26,230.50$ in the District of Columbia (D.C.). The average overall annual cost of having heart disease, according to Medicaid, is $\$ 25,711.44$, ranging from $\$ 20,571.70$ in Arkansas to $\$ 34,493.70$ in D.C. All adults in custody age 50 and older cost $8 \%$ more than the average cost to incarcerate an adult. The average annual cost to incarcerate someone over 49 is $\$ 76,600.87$ in Alabama, ranging from $\# 36,842.96$ to $\$ 460,357$ in New Mexico. 
Table 1.2 Average Costs of Incarceration

\begin{tabular}{llllll}
\hline \multicolumn{1}{c}{ Variable } & \multicolumn{1}{c}{$\mathbf{N}$} & Min (state) & Max (state) & Mean & SD \\
\hline $\begin{array}{l}\text { Dependent } \\
\text { Variable }\end{array}$ & 14,326 & $\$ 71,342$ & $\$ 521,261$ & $\$ 122,570$ & $\$ 123,370$ \\
$\begin{array}{l}\text { Avg. Cost of } \\
\text { Incar. }\end{array}$ & 14,349 & $\$ 15,433(\mathrm{AL})$ & $\$ 72,423(\mathrm{NM})$ & $\$ 35,018$ & $\$ 16,353$ \\
$\begin{array}{l}\text { Heart } \\
\text { Disease Cost }\end{array}$ & 14,349 & $\$ 20,572(\mathrm{AK})$ & $\$ 34,494(\mathrm{D} . \mathrm{C})$. & $\$ 25,711$ & $\$ 3,256$ \\
$\begin{array}{l}\text { Diabetes } \\
\text { Cost }\end{array}$ & 14,348 & $\$ 11,087(\mathrm{WA})$ & $\$ 26,231(\mathrm{D} . \mathrm{C})$. & $\$ 20,417$ & $\$ 2,821$ \\
Age Cost & 14,472 & $\$ 36,843(\mathrm{AL})$ & $\$ 460,537(\mathrm{NM})$ & $\$ 76,601$ & $\$ 123,554$ \\
West & 6,465 & $\$ 74,607$ & $\$ 517,014$ & $\$ 126,213$ & $\$ 126,384$ \\
Midwest & 2,742 & $\$ 74,653$ & $\$ 513,877$ & $\$ 121,125$ & $\$ 118,025$ \\
Southwest & 518 & $\$ 74,125$ & $\$ 512,991$ & $\$ 112,667$ & $\$ 115,665$ \\
Southeast & 2,670 & $\$ 74,076$ & $\$ 521,261$ & $\$ 116,881$ & $\$ 117,654$ \\
Northeast & 1,511 & $\$ 74,998$ & $\$ 506,586$ & $\$ 125,905$ & $\$ 131,878$ \\
\hline
\end{tabular}

To assess the relationship between the dependent variable, the cost of incarceration plus the cost of heart diseases, diabetes, and age $(50+)$, and the independent variable, how the average overall costs are associated with the costs of heart disease and diabetes and age, a correlation test using bivariate analysis was conducted (Table 1.3). The bivariate stage of the analysis assesses if there is a relationship between cost of incarceration and having heart disease or diabetes. The Pearson correlation between the two variables shows a significant, small correlation and is positive, indicating that those with heart disease and diabetes are associated with cost increases. There is a significant weak correlation between the independent variable and the cost of heart disease, which is negative. The correlation between the 
independent variable and the cost of incarceration adjusted for age is significant, small, and positive.

\section{Table 1.3 Correlation coefficients across cost measures}

\begin{tabular}{lllll}
\hline & $\begin{array}{l}\text { 1. Avg Cost of } \\
\text { Incarceration }\end{array}$ & 2. Heart Disease & 3. Diabetes & 4. Age (>50) \\
\hline 2. & $-.061^{*}(p=.027)$ & 1 & & \\
3. & $-.050(p=.192)$ & $.111(p=.155)$ & 1 & \\
4. & $-.008(p=.352)$ & $.106 *(p=.000)$ & $.142 *(.001)$ & 1 \\
\hline \multicolumn{5}{l}{$*$ Significant $p$ values $(<.05)}$.
\end{tabular}

\section{Analytical Plan}

To predict the change of the average cost of incarceration, the cost of heart disease, diabetes and the cost of baseline incarceration (no ailments) but adjusted for age, ordinary least squares model is used to analyze the occurrence of heart disease and diabetes among adults in custody, while controlling for other factors. This version of linear regression is used because the dependent variable, cost of incarceration, is continuous and normally distributed. 


\section{Results}

Table 2 depicts each of the OLS models conducted to test the hypotheses that the incarceration of adults with chronic diseases increase the overall cost. Model 1 predicts the change in the cost of incarceration, given the observed fluctuation in the whether or not the adult in custody has heart disease, diabetes, or both. This baseline model explains $2.2 \%$ of the variance $(F=496.4, p<.05)$ in the cost of incarceration, which is understandably low considering that many of the correlates related to chronic illnesses are not yet included. The unstandardized beta coefficient indicates that there is a significant relationship between the increase in cost of incarceration for adults with heart disease or diabetes compared to those who do not have either of these chronic diseases. Specifically, at the baseline, heart disease and diabetes on average account for a $\$ 76,153$ increase in the cost of incarceration before controlling for other measures.

Model 2 of the regression analysis predicts the change in the cost of incarceration given the fluctuation of having heart disease or diabetes and controlling for sex of the adult in custody, age, race, and national state regions. This model explains $29.9 \%$ of the variance $(F=1,337.1, p<.05)$ in the cost of incarceration, displaying some of the correlates related to heart disease and diabetes. The unstandardized beta coefficient indicates a significant relationship between the 
increase in the price of incarceration for adults with heart disease or diabetes. After including the demographic measures, heart disease, and diabetes, on average, account for a $\$ 7,000$ increase in incarceration costs.

\section{Table 2. OLS models assessing relationships between costs while controlling for other factors}

\begin{tabular}{|c|c|c|c|c|c|c|c|c|c|}
\hline \multirow{2}{*}{$\begin{array}{l}\text { Control } \\
\text { measures a }\end{array}$} & \multicolumn{3}{|c|}{ Model 1} & \multicolumn{3}{|c|}{ Model 2} & \multicolumn{3}{|c|}{ Model3 } \\
\hline & $\mathrm{B}$ & SE & $p$ & $\mathrm{~b}$ & SE & $p$ & $\mathrm{~b}$ & $\mathrm{SE}$ & $p$ \\
\hline Heart D / & 76.15 & 3.42 & .000 & & & & & & \\
\hline Diabetes & & & & 7.00 & 2.37 & 0.003 & 27.88 & 21.55 & 0.199 \\
\hline Sex $($ Male=1) & & & & 4.24 & 1.63 & 0.009 & 97.31 & 27.19 & 0.001 \\
\hline Age (Over 50) & & & & 139.82 & 1.87 & 0.000 & 161.54 & 23.58 & 0.000 \\
\hline \multicolumn{10}{|l|}{ Race } \\
\hline (White $=1$ ) & & & & 2.86 & 1.33 & 0.031 & -21.27 & 25.64 & 0.409 \\
\hline \multicolumn{10}{|l|}{ West (ref.= } \\
\hline Northeast) & & & & 4.90 & 2.04 & 0.016 & -35.46 & 25.93 & 0.175 \\
\hline \multicolumn{10}{|l|}{ Midwest (ref.= } \\
\hline Northeast) & & & & 6.09 & 2.35 & 0.009 & -64.54 & 34.07 & 0.061 \\
\hline \multicolumn{10}{|l|}{$\begin{array}{l}\text { Southwest } \\
\text { (ref.= }\end{array}$} \\
\hline Northeast) & & & & -5.03 & 3.90 & 0.197 & -44.59 & 40.07 & 0.269 \\
\hline \multicolumn{10}{|l|}{$\begin{array}{l}\text { Southeast } \\
\text { (ref.= }\end{array}$} \\
\hline Northeast) & & & & 1.55 & 2.34 & 0.509 & -13.32 & 30.22 & 0.660 \\
\hline Cancer & & & & & & & 9.86 & 20.80 & 0.637 \\
\hline Obese & & & & & & & 27.75 & 24.70 & 0.264 \\
\hline Tobacco user & & & & & & & -62.26 & 31.59 & 0.052 \\
\hline Asthma & & & & & & & -11.00 & 25.89 & 0.672 \\
\hline Exercise & & & & & & & -56.39 & 19.38 & 0.005 \\
\hline R-squared & \multirow{3}{*}{\multicolumn{3}{|c|}{$\begin{array}{c}.033 \\
496.4(.000) \\
1\end{array}$}} & \multirow{3}{*}{\multicolumn{3}{|c|}{$\begin{array}{c}.299 \\
726.28(.000) \\
8\end{array}$}} & \multirow{3}{*}{\multicolumn{3}{|c|}{$\begin{array}{c}.543 \\
8.13(.000) \\
13 \\
\end{array}$}} \\
\hline F statistic (p) & & & & & & & & & \\
\hline $\mathrm{df}$ & & & & & & & & & \\
\hline
\end{tabular}

a. Values are measured in thousands of 2021 USD.

Model 3 of the regression analysis predicts the change in cost of incarceration given the fluctuation of having a heart disease or 
diabetes while controlling for demographics, region, cancer, obesity, tobacco use, asthma and exercise. This model explains $54.3 \%$ of the variance in the overall cost of incarceration $(F=.543, p<.05)$, indicating that the measures that you include in the model are the primary measures that capture correctional costs. White AICs, on average price approximately $\$ 21,270$ less than non-White AICs. This is primarily because individuals of color are often afflicted with many chronic and costly illnesses (Artiga, 2020). While this estimate did not reach significance in the third model, its overall context is important when considering health costs. Adults in custody that use tobacco significantly estimate a decrease of $\$ 6,226$ incarceration costs, which is contrary to what is predicted as smoking is a risk factor for heart disease and diabetes. This relationship is further explained in the discussion. The variable currently has asthma did not reach significance and estimating a decrease of $\$ 1,100$ in cost. Adults in custody who reported participation in daily exercise or physical activity is significant and estimates that exercise decreases the cost of incarceration by $\$ 5,639$ as it is a protective factor to heart disease or diabetes. 


\section{Discussion}

This exploratory research examined costly chronic health diseases using survey data of adults in custody across the nation. According to the World Health Organization, chronic illness and diseases are the leading cause of death and disability worldwide (WHO, 2002). The World Health Organization states that noncommunicable diseases are responsible for almost $70 \%$ of deaths and is due to four major risk factors: tobacco use, physical inactivity, unhealthy diet, and excessive alcohol and drug use. The most prevalent chronic diseases are heart disease, diabetes, asthma, cancer, chronic kidney disease, arthritis, and chronic obstructive pulmonary disease. This analysis examines two chronic diseases, most common in the sample, heart disease, and diabetes.

Incarceration and health disparities disproportionately effect minorities and risk factors for chronic diseases are rooted in social inequalities (Davis, 2007 \& Bailey, 2017). The prevalence of chronic disease has steadily increased over the last few decades (US Department of Health and Human Services). Health promotion and prevention of chronic illness is crucial to improve overall quality of life while also addressing the costliest diseases (NCCDPH, 2020). The impact of chronic disease risk factors is especially prevalent in prisons; promotion of prevention factors may not only improve the health of 
adults in custody but could also save reduce the cost of spending per adult in custody.

The results indicate that adults in custody that currently have heart disease and diabetes are significantly associated with an increased cost of incarceration in Model 1 and Model 2 of the linear regression. It is not a surprise that the association is strong, as these chronic diseases account for most health care costs within the general public (CDC, 2021). This finding highlights an opportunity for correctional facilities to address these illnesses, improve health among those incarcerated and have the potential to decrease total costs.

In Model 2, the occurrence of heart disease and diabetes is significant and accounts for the higher cost of incarceration, as predicted. The control variable, sex, coded for males, is significant and accounts for a $\$ 4,240$ increase in the incarceration costs; explained because males are more likely to be incarcerated than females, and male adults in custody account for most of the data in this sample. The age variable, coded for adults in custody over age 50 , is significant and accounts for an increase of $\$ 139,820$ on top of the cost of incarceration. The increased cost of housing elderly adults in custody is precise in past research. According to the National Institute of Corrections, it costs three times as much to house an elderly adult in custody than a younger adult; on average, 55-year-olds and older cost 
$8 \%$ more than adults in custody ages 54 and younger (Bureau of Justice Statistics, 2013). Age is a significant risk factor for noncommunicable chronic disease, specifically heart disease, type 2 diabetes, and cancer (Shlisky, 2017). The results explain that the adults in custody with heart disease or diabetes are more likely to be age 55 or over and incur more costs due to these chronic diseases. The race variable coded for adults in custody who identify as white is significant and accounts for a $\$ 2,860$ increase in the incarceration costs. Although on average, Whites in The United States are less likely than Blacks and Hispanics to have heart disease or diabetes (Raghupathi,2018), the majority in the sample of adults in custody are White, which is reflected in the results. The region variables represent a clump of states categorized by location. Northeast is used as the reference group and is not included in the analysis because the adults in custody incarcerated in this region are the costliest compared to the other areas. Adults incarcerated in the West account for an increase of $\$ 4,900$, in the Midwest account for an increase of $\$ 6,090$. The variables for Southwest and Southeast are insignificant. The sample of adults in custody in the Southwest region accounts for a decrease of $\$ 5,030$ and the adult sin the Southeast accounts for an increase of $\$ 1,550$. These variables are likely insignificant due to the population variation of those incarcerated in these regions. 
The results of this analysis provide insight that chronic diseases like heart disease and diabetes should be addressed and with health promotion and prevention, could cut overall costs. While saving money, the changes to promote health and wellness of imprisonment may benefit the adults in custody and have an impact on offenders post their release. The CDC outlines seven behavior changes to prevent chronic disease (2021). These are to quit smoking, eat healthy, get regular physical activity, avoid drinking too much alcohol, get screened, get enough sleep and know your family history. These preventable measures are behaviors that cannot be forced upon someone. The environment of health can influence the adherence to these behaviors and can promote chronic disease prevention. Addressing these risk factors can be a daunting task for anyone. Managing them while incarcerated is more challenging and is dependent on the prison environment.

The first risk factor the CDC identifies is smoking. Smoking is embedded within prison culture, and secondhand smoke from other adults in custody or staff can make it challenging to quit smoking (Brown, 2018). Smoking tobacco is most associated with cancer risk, although smoking is also a risk factor for heart disease and diabetes (FDA, 2020). Smoking bans and restrictions exist in some correctional facilities to protect people who do not want to be negatively affected 
by secondhand smoke (Spaulding, 2018). Justifications for smoking bans are also due to other cost-savings and a decrease in hospitalizations and medical care. Tobacco bans and restrictions have been found to decrease tobacco-related death, burns, injuries, and secondhand smoke (Spaulding, 2018). Banning tobacco within correctional facilities is debated because it deprives a person of their rights that are not lawfully taken from them. A smoking restriction should also address tobacco addiction to make lasting changes in a person's health.

A meta-analysis found that smoking cessation interventions effectively reduce smoking during incarceration, reduce short-term health effects, and cut related medical costs (Spaulding, 2018). The impact of smoking cessation in prison is unclear post-release. Restrictions should incorporate behavior change and treatment while in prison and after to ensure lasting change. In the results of Model 3 tobacco significantly predicted a decrease in overall costs of incarceration, which is inconsistent with prior research that finds tobacco as a risk factor for chronic disease (CDC, 2020). To further unpack this relationship, a t-test was used to examine the mean cost between heart disease/diabetes when broken out by tobacco use, asthma, and being 55 years old or older. The vast majority of adults in custody that smoke are under age 55 and do not currently have 
heart disease or diabetes. The average mean costs displayed in Table 3 provide an explanation for this result. The average cost of incarceration for someone with heart disease or diabetes is higher for than those without heart disease or diabetes regardless of tobacco use. There are 1,512 respondents that are younger than age 55 and smoke and only 209 respondents that are older than 55 and smoke, explaining why not smoking results in a higher cost. Heart disease is most likely diagnosed in people over 55 and diabetes onsets at age 45 on average (Prasad, 2012) A study of middle-aged people who smoke were diagnosed with a chronic disease on average at age 67 (Quinoes, 2017). Thus, younger adults in custody are more likely smoking tobacco but are not yet experiencing the consequences from it. Similarly, asthma was also significantly associated with a slight decrease in cost of incarceration. Table 3, displays that the average cost for someone with asthma is significantly higher than someone without asthma, regardless of having heart disease or diabetes. There were more respondents with asthma who were younger and without a current disease than those who were older or with a current disease. 
Table 3. T-Test to unpack select variables of Model 3

\begin{tabular}{lcc|lr}
\hline $\begin{array}{l}\text { Average Mean } \\
\text { Costs a }\end{array}$ & $\begin{array}{l}\text { Has Heart } \\
\text { Disease or } \\
\text { Diabetes }\end{array}$ & $\begin{array}{l}\text { Std. } \\
\text { Deviation }\end{array}$ & $\begin{array}{l}\text { No heart } \\
\text { disease or } \\
\text { diabetes }\end{array}$ & $\begin{array}{l}\text { Std. } \\
\text { Deviation }\end{array}$ \\
\hline $\begin{array}{l}\text { Tobacco } \\
\text { Currently smokes }\end{array}$ & $\$ 188.38$ & $\$ 184.13$ & $\$ 106.60^{*}$ & $\$ 100.76$ \\
$\begin{array}{l}\text { Does not smoke } \\
\text { Asthma }\end{array}$ & $\$ 191.76$ & $\$ 185.20$ & $\$ 116.36^{*}$ & $\$ 113.77$ \\
$\begin{array}{l}\text { Currently has } \\
\begin{array}{l}\text { asthma } \\
\text { No asthma }\end{array}\end{array}$ & $\$ 170.10$ & $\$ 171.44$ & $\$ 112.74$ & $\$ 107.79$ \\
$\begin{array}{l}\text { Age } \\
55 \text { and older }\end{array}$ & $\$ 167.23$ & $\$ 169.84$ & $\$ 109.59$ & $\$ 102.74$ \\
54 and younger & $\$ 242.64 *$ & $\$ 205.52$ & $\$ 219.35^{*}$ & $\$ 197.99$ \\
& $\$ 82.73^{*}$ & $\$ 5.53$ & $\$ 83.03^{*}$ & $\$ 5.67$ \\
\hline
\end{tabular}

a Values are measured in thousands of 2021 USD.

The second behavior change to prevent chronic diseases is to eat a healthy balanced diet of fruits, vegetables, whole grains and lean protein. According to the CDC if you are overweight, losing about $6 \%$ of your body weight can help prevent and delay chronic disease (2020). Prison food is widely known to be bad, and in some cases inedible, spoiled and often lacking nutrition according to a survey done bby Impact Justice (Soble, et al., 2020). Impact Justice investigated prisons across the nation in order to understand the nutritional value of prison food. They found that the majority of meals served in prison are loaded with carbs, sugar, sodium and highly processed foods (Soble, et al., 2020). More than half of the adults in custody that responded to Impact Justice's surveys said they rarely or never have access to fresh fruits or vegetables. Prison food rarely meets the 
minimum recommended amount of nutrients and is often supplemented with fortified foods or beverages that are not as effective as fresh whole foods at delivering nutrients.

Getting regular physical activity is a protective factor for heart disease, diabetes among other chronic diseases (WHO, 2020). In this analysis, adults in custody that participated in physical activity predicted a decrease in cost of incarceration. In a study assessing the role of physical activity and heart disease prevention in prisoners found that supervised exercise training is an effective coping strategy to deal with the stress of incarceration and that sports programs may be a useful way to improve physical and mental health of prisoners as well as in decreasing health related risk factors (Papa, 2021). Factors of stress linked to the isolation and loneliness within prison and the stress of prison cultures of violence can also play into the likelihood of chronic illness prevalence. Quality sleep is connected with reduced stress and reduced seriousness of chronic disease. Sleep was not evaluated in this study but should be an important aspect in preventing disease and promoting health.

Ultimately the third model of the results, the associated costs due to chronic disease was found to be insignificant. This can be explained by unincluded costs in my analysis. Vera's analysis of the price of prisons found that nearly two-thirds of prison expenditures are 
due to staffing, including salaries, overtime pay and benefits (Mai, 2016). The states with higher average staff salaries and a large prison population have higher than average costs of incarceration per adult in custody (Mai, 2016). These costs help to explain that in my analysis the r-squared only accounted for $54 \%$ of variance.

The public health disparities that occur outside of prison walls are magnified within incarceration and there is clear evidence that incarceration does not equally affect the population (Udo, 2019). Communities most affected by incarceration are the same communities with the greatest health inequalities (Bowleg, 2020). Race, class, and gender disparities in the United States are complex and rooted in various social injustices, including the legacy of white supremacy, systemic racism and economic inequalities. The United Nations Human Rights Watch adopted and proclaimed basic principles for the treatment of prisoners and number nine on the list states "Prisoners shall have access to the health services available in the country without discrimination on the grounds of their legal situation" (World Health Organization, 2021). If and access to adequate care is not efficient and is putting adults in custody at risk for chronic diseases, future policies should understand these effects when implementing medical and health services for inmates. The United States is a part of the United Nations, yet this participation is very 
much a ceremonial participation. In many ways the United States does not recognize the human rights aspects and violates a lot of the expectations. 


\section{Limitations}

The specific costs of incarceration evaluated in this study looked at costs accrued per adult in custody and did not factor in the variation staffing or building costs. Each baseline average cost accounts for the total costs of incarceration, this includes resources, maintenance and staff salaries and is then divided by the number of adults in custody at the associated prison. First, this study did not include variables regarding staffing and building maintenance costs and future research should include this to predict the relationship between health spending. This is noteworthy although, the average annual price of prison spending calculations from Vera's research in 2015 that was used in the analysis did include building and staffing costs, the direct relationship is not assessed. Second, the measure of exercise was calculated by dichotomizing a survey question that asked the respondents whether or not they got physical activity within the pat 24 hours. This survey question may have not accurately measured the number of adults in custody participating in physical activity on a regular basis. Implementing ways for adults in custody to get physical activity, exercise, play sports or lift weights is an easy and cheap way for prisons to increase overall wellbeing. Third, the data used in this study is from 2004 and while this survey represents the nation's prison population well, the overall prison population has decreased since 
then. The overall prevalence of chronic disease continues to rise, and prison organizations should consider how this will affect the prison population. A current and more in-depth study of the health of inmates in custody and how their environment plays a role is needed. Lastly, this study only focused on the chronic diseases heart disease and diabetes, due to their high associated costs and mortality rates. An in depth look at other non-communicable chronic conditions like Alzheimer's, asthma, cancer, kidney disease, stroke may also be prevalent within carceral populations. Managing and preventing all diseases, including transmissible illness is important to protect the human rights of adults in custody and could present means for saving government tax dollars. 


\section{Implications and Future Research}

The United States spends $\$ 776.2$ billion dollars on Medicare, $\$ 748.8$ billion dollars on health care and 72.1 billion on the administration of justice, a total of $24 \%$ of their total spending in 2019 according to the Monthly Treasury Statement (U.S. Government). Prevention of illness would not only save the government money, but the overall quality of life in the United States would improve as baseline health levels rise. This study has presented analysis that suggests chronic disease within incarcerated populations is associated with a higher average cost of housing adults in custody. The associated costs are more likely for older adults in custody and as chronic disease is not easily curable, a cost saving solution would be to give early release options for older adults in custody. Substantial research finds that as people age, criminal behavior decreases (Britt, 2020); thus early release for elderly adults in custody who may be worsening their risk of chronic disease complications should be considered by corrections administration.

The high costs of health care and associated costs of chronic disease in this study highlight the opportunity for future research. Evidence-based practices that are known to reduce health related illness and improve overall wellbeing should be evaluated within the confines of prison. Prison farming and gardening programs are an 
integral to the prison system in England (Devine-Wright, 2019). Providing adults in custody with such programs to promote contact with the natural environment, supplement diets with fresh food and increase physical activity can improve health and over wellbeing (Devine, Wright, 2019). Such programs should be evaluated in the United States and prison bureaus should think about ways, like the garden programs, that can improve livelihood.

As stated in the introduction, prisons do not operate in a vacuum, they are an integral part of the community and contribute to the greater economy. State and private prisons could work together with the local community to provide quality resources to adults in custody. Prisons could buy local produce weekly from a nearby farm to support the community and improve health. The Oregon State Correctional Institute has a greenhouse located on prison grounds and grows produce which is distributed between the prison cafeteria and donated to local food banks (Oregon State University, 2021). This program provides adults in custody with job-skills, knowledge in topics of ecology, improves their diet and positively impacts the community. Prisons have the opportunity to improve public health equity and evaluation of the cost effectiveness of programs like the greenhouse program will provide guidance to state legislators and prison management staff. 
Educating adults in custody about their physical and mental health can present a variety of ways to reduce disease. Working with local community members to provide opportunities for adults in custody to learn about a variety of ways to be live an active lifestyle, like taking a yoga or dance class. Incentivizing exercise ad activities within the prison daily routine can promote physical activity. Prisons could not only provide healthy food but also provide resources about nutrition and educate adults in custody about how to eat a balanced diet.

Improvements to the prison environment, like adequate exercise opportunities, serving healthy food, promoting quality sleep and restricting tobacco accessibility, are beneficial for the wellbeing of all adults in custody as well as staff and management. Implementing small changes to improve health and educate adults in custody about risk factors supports lasting change within an already marginalized population. This study highlights factors of the prison population that improve quality of life as well presenting a direction for prison bureaus to efficiently decrease the overall spending per adult in custody. 


\section{References}

Ahalt, C., Binswanger, I., Steinman, M., Tulsky, J., Williams, B. (2011). Confined to ignorance: The absence of prisoner information from nationally representative health data sets. $J$ Gen Intern Med 27(2): 160-6.

Artiga S, Orgera K, Pham O. (2020) Disparities in health and health care: five key questions and answers. The Henry J. Kaiser Family Foundation. Available at: https://www.kff.org/disparitiespolicy/issue-brief/disparities-in-health-and-health-care-five-keyquestions-and-answers/.

Bailey, Z., Krieger, N., Agenor, M., Graves, J., Linos, N., Basset, M. (2017). Structural racism and health inequities in the USE: evidence and interventions. The Lancet. 389(10077), 14351463.

Begussie, B., Geller, A. (2017). The root causes of health inequity. Communities in Action: Pathways to Health Equity.

Benjamin E.J., Virani S.S., Callaway C.W. (2018) Heart disease and stroke statistics-2018 update. American Heart Association. 137(7-492).

Bowleg L. (2020). Reframing Mass Incarceration as a Social-Structural Driver of Health Inequity. American journal of public health. 110(S1), S11-S12. doi.org/10.2105/AJPH.2019.305464 
Britt, C.L. (2019). The Oxford handbook of developmental and lifecourse criminology: age and crime. United States: Oxford University Press.

Bronson, J (2018). Justice expenditure and employment extracts, 2015-Preliminary. Bureau of Justice Statistics. 13-146.

Carson, E., Noonan, M. (2013). Aging and mortality in the state prison population. Bureau of Justice Statistics. U.S. Department of Justice.

https://www.accjh.org/sites/default/files/presentations/S2_Speci al\%20Populations_Aging_Aging\%20and\%20mortality\%20in\%20 the\%20state\%20prison\%20population.pdf

Centers for Disease Control and Prevention. (2020). National Center for Chronic Disease Prevention and Health Promotion.

Devie-Wright, H., Bayutt, M., Meek, R. (2019). Producing food in English and Welsh prisons. Appetite, 143. doi.org/10.1016/j.appet.2019.104433.

Dominguez, P., Raphael, S. (2015). The role of the cost-of-crime literature in bridging the gap between social science research and policy making. Criminology \& Public Policy, 14(4), 589-632. Ginn, S. (2012). Prison environment and health. The BMJ, 345. doi: $10.1136 /$ bmj.e5921 
Greene, M., Ahalt, C., Stijacic-Cenzer, I., Metzger, L., Williams, B. (2018). Older adults in jail: high rates and early onset of geriatric conditions. Health \& Justice, 6(3). doi.org/10.1186/s40352-018-0062-9

Hughes, (2003) Justice expenditure and employment in the United States. Bureau of Justice Statistics.

James, N. (2018). Risk and needs assessment in the federal prison system. Congressional Research Report, 7-5700, R44087. www.crs.gov

Lemieux, C. M., Dyeson, T. B., \& Castiglione, B. (2002). Revisiting the literature on prisoners who are older: Are we wiser? The Prison Journal, 82, 440-458.

Loeb, S., AbuDagga, A. (2006). Health-related research on older inmates: an integrative review. Research in Nursing \& Health. $29,556-565$.

Marquart, J., Merianos, D., Cuvelier, S.J., Carroll, L. (1996). Thinking about the relationship between health dynamics in the free community and the prison. Crime \& Delinquency. 42(3), 331360.

McKillop, M., Boucher, A. (2018). Aging prison populations drive up costs. Pew Trusts. 
Monthly Treasury Statement (2020). Federal spending by category. U.S Department of Treasury. Available at: https://datalab.usaspending.gov/americas-financeguide/spending/categories/.

National Cancer Institute. (2018). Cancer Prevalence and Cost of Care Projections. U.S Department of Health and Human Services. https://costprojections.cancer.gov/

News Release (2012). Old behind bars the aging prison population in the United States. Human Rights Watch. https://www.hrw.org/report/2012/01/27/old-behind-bars/agingprison-population-united-states.

Nichols, G.A., Bell, T.J., Pedula, K.L., O’Keeffe-Rosetti, M. (2010). Medical care costs among patients with established cardiovascular disease. The American Journal of Managed Care. 16(3)

Nilsen, E. (2007). Decency, dignity, and desert: Restoring ideals of humane punishment to constitutional discourse. University of California, Davis, 41(1), 111-175.

Nowotny, K.M., Cepeda, A., James-Hawkins, L., Boardman, J.D. (2015) Growing old behind bars: Health profiles of the older male inmate population in the United States. Journal of Aging and Health. 28(6): 935-956. doi: 10.1177/0898264315614007 
Oregon State University. (2021). NORCOR Greenhouse. Available at https://extension.oregonstate.edu/mg/wasco/norcorgreenhouse.

Prasad, S., Sung, B., \& Aggarwal, B. B. (2012). Age-associated chronic diseases require age-old medicine: role of chronic inflammation. Preventive medicine. 54, S29-S37. https://doi.org/10.1016/j.ypmed.2011.11.011.

Price, J.H., Khubchandani, J., McKinney, M., Braun, R. (2013). Racial/ethnic disparities in chronic diseases of youths and access to health care in the United States. BioMed Research International, 2013, Article ID 787616.

doi.org/10.1155/2013/787616

Quiñones, A.R., Nagel, C.L., Newsom, J.T. et al. (2017) Racial and ethnic differences in smoking changes after chronic disease diagnosis among middle-aged and older adults in the United States. BMC Geriatr 17(48). https://doi.org/10.1186/s12877017-0438-z.

Restum, Z.G. (2005).Public health implications of substandard correctional health care. American Journal of Public Health. 95(10).

Shlisky, J., Bloom, D. E., Beaudreault, A. R., Tucker, K. L., Keller, H. H., Freund-Levi, Y., Fielding, R. A., Cheng, F. W., Jensen, G. L., 
Wu, D., \& Meydani, S. N. (2017). Nutritional considerations for healthy aging and reduction in age-related chronic disease. Advances in nutrition (Bethesda, Md.), 8(1), 17-26. https://doi.org/10.3945/an.116.013474.

Smoyer, A. B., \& Lopes, G. (2017). Hungry on the inside: Prison food as concrete and symbolic punishment in a women's prison. Punishment \& Society, 19(2), 240255. doi.org/10.1177/1462474516665605

Soble, L., Stroud, K., Weinstein M. (2020). Eating behind bars: Ending the hidden punishment of food in prison. Impact Justice. impactjustice.org/impact/food-in-prison/\#report

Spaulding, A., Eldridge, G., Chico, C., Morisseau, N., Drobeniuc, A., Fils-Aime, R., Day, C., Hopkins, R., Jin, X., Chen, J., Dolan, K. (2018). Smoking in correctional settings worldwide: prevalence, bans, and Interventions, Epidemiologic Reviews, 40(1), 82 95. https://doi.org/10.1093/epirev/mxy005.

Tonry, M., (2015). The fog around cost-of-crime studies may finally be clearing. Criminology \& Public Policy, 14: 653-671. doi.org/10.1111/1745-9133.12170

Travis, J., Western, B., Redburn, S. (2014). The growth of incarceration in the United States: Exploring causing and consequences. National Academies Press. 258. 
Tsai, A.G., Williams, D.D., Glick, H.A. (2011). Direct medical cost of overweight and obesity in the USA: a quantitative systematic review. Obes Rev. 12(1):50-61. doi: 10.1111/j.1467789X.2009.00708.x

United Nations Foundation (2021). Global Health. Available at https://unfoundation.org/what-we-do/issues/global-health/. U.S. Department of Health and Human Services. (2018). Summary health statistics: national health interview survey. Centers for Disease Control and Prevention, National Center for Health Statistics. https://www.hhs.gov.

Wacquant, L. (2002) Four strategies to curb carceral costs: on managing mass imprisonment in the United States. Studies in Political Economy, 69:1, 19-30, DOI:

$10.1080 / 19187033.2002 .11675178$

Watson, R., Stimpson, A., Hostick, T. (2004). Prison health care: a review of the literature. International Journal of Nursing Studies. $41(2), 119-128$.

Woodall, J.,Viffiani, N., Dixey, R., Southe, J. (2014). Moving prison health promotion along: towards an integrative framework for action to develop health promotion and tackle the social determinants of health. Criminal Justice Studies. 27(4), 114132. 
